\title{
Systems of Care and Natural History of Traumatic Brain Injury
}

\author{
DOUGLAS I. KATZ | NATHAN D. ZASLER I ROSS D. ZAFONTE
}

\section{INTRODUCTION}

Traumatic brain injury (TBI) is a major worldwide health care problem, and systems of care should ideally provide a continuum of optimal treatment and services to address acute, post-acute, and chronic medical and nonmedical needs. Challenges include the large numbers affected, particularly among younger and older age groups; complexity of pathophysiology over a broad range of severities; varied and often underrecognized clinical effects, particularly cognitive and behavioral; and prolonged natural history and potential lifelong needs. Components of care involve prevention, emergency medical services, acute hospital care, acute inpatient rehabilitation, subacute/skilled nursing facility, outpatient rehabilitation, residential rehabilitation, avocational and vocational services, special education, community-based services, long-term care, and case management. Obtaining services for individuals with TBI can be challenging in the face of constrained payer support and limited professional and community resources. An understanding of brain injury pathophysiology-associated clinical consequences, natural history, and prognosis can aid in applying proper services for patients along the continuum of care and helps assure more effective and efficient use of resources. This chapter reviews the systems of care available for TBI and provides a discussion of how pathophysiology and natural history can inform treatment choices and the flow of care for individuals with TBI.

\section{SCOPE OF THE PROBLEM AND THE CHARACTERISTICS OF TRAUMATIC BRAIN INJURY}

Systems of care for persons with TBI should account for the particular characteristics of this disorder. First, TBI is a large problem. TBI is among the most common of serious neurological disorders and a leading cause of death and disability $^{1}$ that can impose a tremendous burden on patients, families, and society. It is a major problem in all countries, although reported incidence varies considerably depending on TBI definitions and availability of surveillance data. The vast majority of injuries are considered mild and many go unrecognized because they do not present for health care.
In the United States, in 2014, there were 2.87 million TBIrelated ED visits, hospitalizations, and deaths. ${ }^{2}$ The prevalence of TBI is high, and a meta-analysis suggested that $12 \%$ of adults had experienced a TBI associated with loss of consciousness. ${ }^{3}$ One survey of persons in the United States (Colorado) found that $42.4 \%$ experienced at least one TBI in their lifetime. ${ }^{4}$ There are an estimated 3.2 million people living with disability from TBI in the United States. ${ }^{1,5}$ The economic costs are enormous; the global economic burden is estimated at $\$ 400$ billion. ${ }^{6}$ Systems of care should be structured to allocate resources for the large number of people who are affected by TBI over a range of severities.

Second, TBI is more common in younger than older individuals. ${ }^{7}$ Individuals younger than 30, mostly males, make up a large proportion of those affected by TBI. It is the leading cause of death and disability in children and adolescents. ${ }^{2}$ TBI frequently impacts people in the later stages of adolescent development or early adulthood. Therefore, TBI typically disrupts important periods of the life cycle that involve completing formal education, maturing social development, emerging vocational productivity, achieving adult independence, beginning spousal relationships, and child rearing. Persons aged 75 and older have the highest rates of hospitalization and death. ${ }^{2}$ Older persons present particular problems related to aging including comorbidities, often have slower and less complete recovery, and have greater vulnerability to complications of injury and treatment. 8,9 Systems of care must address needs that include special educational requirements, independent living, vocational training and supports, and supports for family members.

Third, TBI more commonly affects populations at higher risk for injury and comorbidities. Older populations are at high risk for TBI after falls. Sport-related concussion is a frequent cause of TBI and, although inconsistently presenting for clinical evaluation, the reported incidence has been increasing, in part related to greater awareness by professionals and the public. ${ }^{10}$ People with preexisting problems such as substance abuse, learning disability, behavioral disorders, psychiatric disorders, and other risk factors are more prone to injuries. ${ }^{11}$ There is a high rate of TBI history in prison populations. ${ }^{12}$ In addition, persons with brain injury are more prone to psychiatric comorbidities and 
psychosocial difficulties following injury. Systems of care must consider these risk factors with respect to injury prevention, their interactions with problems related to injury, and their potential detrimental effects on recovery.

Fourth, the most important and consistent effects of TBI involve cognitive, emotional, and behavioral functioning. Persistent motor and sensory perceptual problems also occur in varying amounts, more likely in those with more severe injuries. Neuro-ophthalmological and vestibular problems are common even after more mild injuries. Cognitive and behavioral problems present challenges to the health care system because they are often more difficult to recognize, characterize, and treat than traditional medical and physical problems. Persons with TBI may not have any physical markers or obvious signs of injury, though there may be profound effects on an individual's ability to function, resulting from cognitive, behavioral, and other injury-related problems. Criteria for medical rehabilitation reimbursement, length of stay, and utilization decisions are often centered more on physical and motor issues that affect function and less on cognitive and behavioral treatment issues. Some insurance payers even exclude coverage for cognitive rehabilitation, although there is a large body of evidence to support the efficacy of a variety of cognitive rehabilitation strategies and models. ${ }^{13-15}$ Systems of care must support proper assessment and treatment of cognitive and behavioral problems after TBI, even though they may not fit the characteristics of medical rehabilitative systems that were originally developed for medical and physical disabilities.

Fifth, TBI, especially more severe injuries, can have a relatively extended natural history and lifelong effects. Recovery from TBI may be more protracted than most other acquired injuries or neurological disorders that evolve more quickly and it may extend over a relatively longer portion of the life span, since it often occurs at an earlier stage of life than most other catastrophic neurological disorders. The natural history of TBI has a longer horizon than most other acquired injuries or neurological disorders of similar severity, and systems of care for TBI need to recognize the potentially prolonged recovery timetable. Although the prospects for earlier and more complete resolution of problems is greater for milder injuries, persisting problems can occur with mild TBI for a variety of reasons. ${ }^{16,17}$ The course of recovery after TBI is highly individualized depending on the particular mix of pathophysiological factors, personal factors, comorbidities, psychosocial factors, and other issues. However, recovery after TBI has a somewhat characteristic course, with a variety of recognizable cognitive, behavioral, and sensorimotor syndromes at different stages of recovery. An appreciation of the natural history of TBI is essential in assessing the individual with TBI, and applying treatment and services effectively and appropriately at different stages of recovery.

Sixth, TBI should be considered a chronic disease process and not a single event. ${ }^{18}$ TBI often causes irreversible pathological changes, persisting neurological deficits, reduced life expectancy, and is associated with an increased risk of a variety of comorbidities, including seizures, endocrine dysfunction, sleep disorders, and psychiatric disorders. ${ }^{19}$ TBI may be a risk factor for late neurodegenerative disorders, ${ }^{20,21}$ and repetitive trauma can result in a variety of neuropathological findings including a distinct, tau-related, neurodegenerative disorder, chronic traumatic encephalopathy. ${ }^{22,23}$
Finally, TBI is a disorder with a wide variety of pathophysiological effects, a broad range of severities, and a multitude of problems that can occur as the result of injury. Persons with apparently similar injuries may have profound differences in their clinical presentation, course of recovery, secondary problems, response to interventions, and ability to reintegrate into community. Systems of care should have a breadth of treatments and services to intervene for the variety of problems that can occur after TBI and the flexibility to move persons with TBI through the system and individualize care as their needs change and evolve at different times post-injury.

\section{THE DEVELOPMENT OF SYSTEMS OF CARE}

The provision of a comprehensive continuum of care for persons with TBI is an enormous challenge given the characteristics of TBI outlined earlier and the wide range of services that should be provided to large numbers of people, over relatively long periods of time. Consumers, providers, payers, and policy makers wrestle with the challenges of creating effective and efficient systems of care for TBI, balancing coverage needs with resource limitations and fiscal pressures. Resources for patients with TBI include acute and post-acute medical care; rehabilitative services in hospital settings, in nursing facilities, at home, in the community, and in supervised residential settings; psychosocial services; educational and vocational services; and a variety of other support services.

In the United States, the development of systems of care for persons with TBI evolved in the 1970s and 1980s. In part, the systems that developed for care of patients with TBI were influenced by systems of care that were already developing for persons with spinal cord injury (SCI). Prior to the development of specific programs for persons with TBI, patients were frequently treated in psychiatric facilities, nursing homes, or more general rehabilitation facilities. The Rehabilitation Services Administration and NIDHR (which was to become NIDRR and NIDILRR, the National Institute on Disability, Independent Living, and Rehabilitation Research), which had funded SCI model systems in the early 1970s, also funded two model system projects for TBI in 1978 at Stanford and New York universities. ${ }^{24}$ The recommendations from these projects helped promote the development of interdisciplinary, dedicated TBI programs with services across the continuum of recovery. As programs began to develop, the lack of organized planning led to an initiative by the NIDRR under the Department of Education in 1987 to fund five TBI Model Systems demonstration projects..$^{25}$ This has expanded to 16 TBI Model Systems Projects funded by NIDILRR throughout the country, in part aimed at gathering information to improve comprehensive systems of care for patients with TBI. The components of these model systems of care include emergency medical services, acute neurosurgical care, comprehensive rehabilitation services, long-term interdisciplinary follow-up, and rehabilitation services, as well as what were termed optional services, including behavior modification programs, home rehabilitation services, case management, and community-living options. ${ }^{25} \mathrm{~A}$ key portion of this program has been longitudinal and project-specific-based research. 
Beginning in the mid-1980s, the Commission on Accreditation of Rehabilitation Facilities (CARF), now known as CARF International, developed standards for TBI rehabilitative care by establishing specialized accreditation for TBI programs. CARF International provides accreditation for brain injury programs among five categories: comprehensive integrated inpatient rehabilitative program, outpatient medical rehabilitation program, home and community services, residential rehabilitation program, and vocational services. Other accrediting agencies, such as The Joint Commission in the United States, review and accredit rehabilitation hospitals and offer disease-specific certifications in areas such as brain injury and stroke.

An important development in TBI care in the United States was the TBI Act of 1996 passed by Congress to "provide for the conduct of expanded studies and the establishment of innovative programs with respect to traumatic brain injury." Four provisions of the act were: surveillance and prevention under the Centers for Disease Control and Prevention (CDC); basic and applied research to improve diagnosis, therapeutics, and the continuum of clinical care conducted by the National Institutes of Health (NIH); a planning and implementation grant program to the states under the Health Resources and Services Administration; and a consensus conference conducted by the Center for Medical Rehabilitation and Research at NIH. ${ }^{26}$ The NIH consensus conference panel addressed the continuum of care for TBI in their conclusions. The recommendations included that "persons with TBI should have access to rehabilitation services through the entire course of recovery, which may last for many years after the injury" and that "community-based, non-medical services should be components of the extended care and rehabilitation available to persons with TBI." 27

Another important development in the care of persons with TBI in the United States has arisen from the needs of active duty military and veterans of the wars in Iraq and Afghanistan with TBI and posttraumatic stress disorder (PTSD). Systems of care have been developed and expanded among military centers and Department of Veterans Affairs hospitals to screen, diagnose, and treat the large number of military personnel returning from the wars with TBI and PTSD. In 1992, Congress created the Defense and Veterans Brain Injury Center (DVBIC; originally the Defense and Veterans Head Injury Program) to integrate specialized TBI care, research, and education across military and veteran medical care systems, and the role of DVBIC in TBI surveillance, care, and research has grown enormously in recent years. The Departments of Defense and Veterans Affairs have also played a major role in expanding support of research for TBI and clinical care practices and guidelines (e.g., Guidelines for Management of Concussion/mild $\mathrm{TBI}^{28}$ ) that will benefit both military and civilian care.

Concussion in sports has been another area of growing attention in TBI care, including efforts at prevention, early diagnosis, management, and proper determination of return to play. Rapid sideline diagnosis and guidelines restricting immediate or premature return to play and graded return to activities after concussion have been important developments in sports concussion care.

\section{REALITIES OF THE MARKETPLACE}

Systems of care for persons with TBI vary considerably within and between countries. The transition from acute to post-acute treatment and beyond in the continuum of care is particularly variable. Although demonstration projects such as the TBI Model Systems in the United States have presented apparently effective systems of care for persons with TBI, the realities of the marketplace have presented challenges to providing such care and services to all those in need. Corrigan outlined 20 important challenges to meeting the needs of persons with TBI, within the categories of access, availability, appropriateness, and acceptability. ${ }^{26}$ With regard to access, the problems involve identifying and utilizing services, even if they are available. There may be difficulties accessing information about available resources. In the United States, there are multiple public and private payers for health care services with wide variability in coverage, particularly for post-acute care. In addition, there may be coverage from workers' compensation insurance for work-related injuries and automobile insurance for TBI in motor vehicle accidents, especially when associated with no-fault laws, but coverage differs from state to state. Sometimes it is difficult to determine what resources are covered by health insurance, and sometimes coverage is denied even after services are delivered. Families and care providers usually lack road maps to guide access to appropriate resources, and points of entry into the publicly funded system may be unclear. Funding for service systems may have artificial barriers created by narrow eligibility criteria. Services are often fragmented and not well coordinated, and cohesive systems of care are lacking.

Corrigan pointed out a number of availability issues for which the main limiting factor is funding. In the United States, even if available, health insurance may not cover needed services, may severely limit the duration of care, or may direct individuals to centers that are less familiar with the care of persons with TBI. Further, lack of payer support may limit the availability of some services to begin with. Many persons with TBI have no health care funding at all at the time of injury, and budget constraints may limit public insurance funding through Medicaid. When available, health insurance typically covers acute care more fully than rehabilitative care. Coverage usually becomes incrementally more difficult across the continuum of care, from inpatient to outpatient to residential and community services. Health insurance coverage also tends to be more restrictive for cognitive and behavioral services as opposed to more traditional physical rehabilitative and medical treatment. For many cases in the United States, coverage for services must shift from private to public sources such as Medicaid and Medicare over the course of recovery because of limits in coverage for longer term care in many private policies. Public funding has further restraints on long-term coverage. Several states have developed a system of Medicaid waivers to provide long-term home- and community-based services that would otherwise be covered only for institutional settings, such as nursing homes. The fragmentation and limitations in financing of care and services can create a nightmare of coordination for persons with brain injury, their families, and service providers. Clinicians who coordinate care for persons with brain injury must become aware of the complexities of 
reimbursement and the array of alternative sources of funding for TBI care and support in their community.

Other issues affecting the availability of services include geographic limitations, lack of transportation, paucity of appropriate, affordable housing, limitations in resources for children with special needs, and a lack of resources for behavioral and other long-term problems after TBI. ${ }^{26}$ Patients with TBI in rural communities have special challenges in finding services within a reasonable distance. Evidence has supported effective telehealth interventions for management of persons with TBI and caregivers. ${ }^{29,30}$ An expanding role for telehealth medical and rehabilitation services is anticipated in the United States and elsewhere, especially after experiences with telehealth during the COVID-19 pandemic. Even when available in a nearby area, transport to and from these services can be a major problem and home services may not be sufficiently expert or available at all for this population. The ability to provide the full array of services, to all age groups, within a reasonable proximity to a person with TBI, with full funding support is an enormous challenge that may never be fully satisfied.

The appropriateness of available resources is also a common problem. Sometimes the reason for inappropriate services is dictated by payer constraints. For instance, since the main payer for long-term care services is Medicaid, if waivers to support home and community services are not available, patients with TBI who cannot return home may be placed in nursing homes, even though community-based services may be more appropriate and available. Even if services are available, programs and professional providers may lack the knowledge and expertise to serve this population. Generalists in a particular discipline or specialty may not have the skills for proper assessment or treatment of the patient with TBI. Accreditation programs such as CARF and the American Academy of Certified Brain Injury Specialists have attempted to set standards and credentialing to assure appropriateness of programming and expertise in treating persons with TBI. Minimum competency recommendations have been published for programs that manage patients with very severe brain injury and disorders of consciousness. ${ }^{31}$ Nevertheless, such expertise may simply not be available in some geographic areas or at certain levels of care. A number of guidelines have been published to promote best practices in care of persons with TBI, ${ }^{32,33}$ but implementation is highly variable. ${ }^{34}$ Sometimes erroneous services are applied because of lack of expertise and sometimes even those with expertise may apply improper or unnecessary services. Inaccurate diagnosis, inappropriate application of treatment at a particular stage of recovery, use of unproven or ineffective treatments, and application of effective treatment to those for whom it would not be of benefit are examples. Use of accurate diagnosis and prognosis is necessary to avoid some of these problems of inappropriate treatment (see Service Delivery in Relation to Natural History of Traumatic Brain Injury). Sometimes even appropriate services are not fully relevant to an individual or family's needs at a particular time or in a particular environment. The acceptability of these services to the goals of the individual with the TBI and their caretakers and how services promote a person's self-actualization is another challenge to the TBI service marketplace. ${ }^{26}$

\section{ESSENTIAL COMPONENTS OF THE CLINICAL CONTINUUM}

The continuum of care for patients with TBI occurs in a variety of settings. Figure 1.1 illustrates the different types of care and how patients may move through these components. The

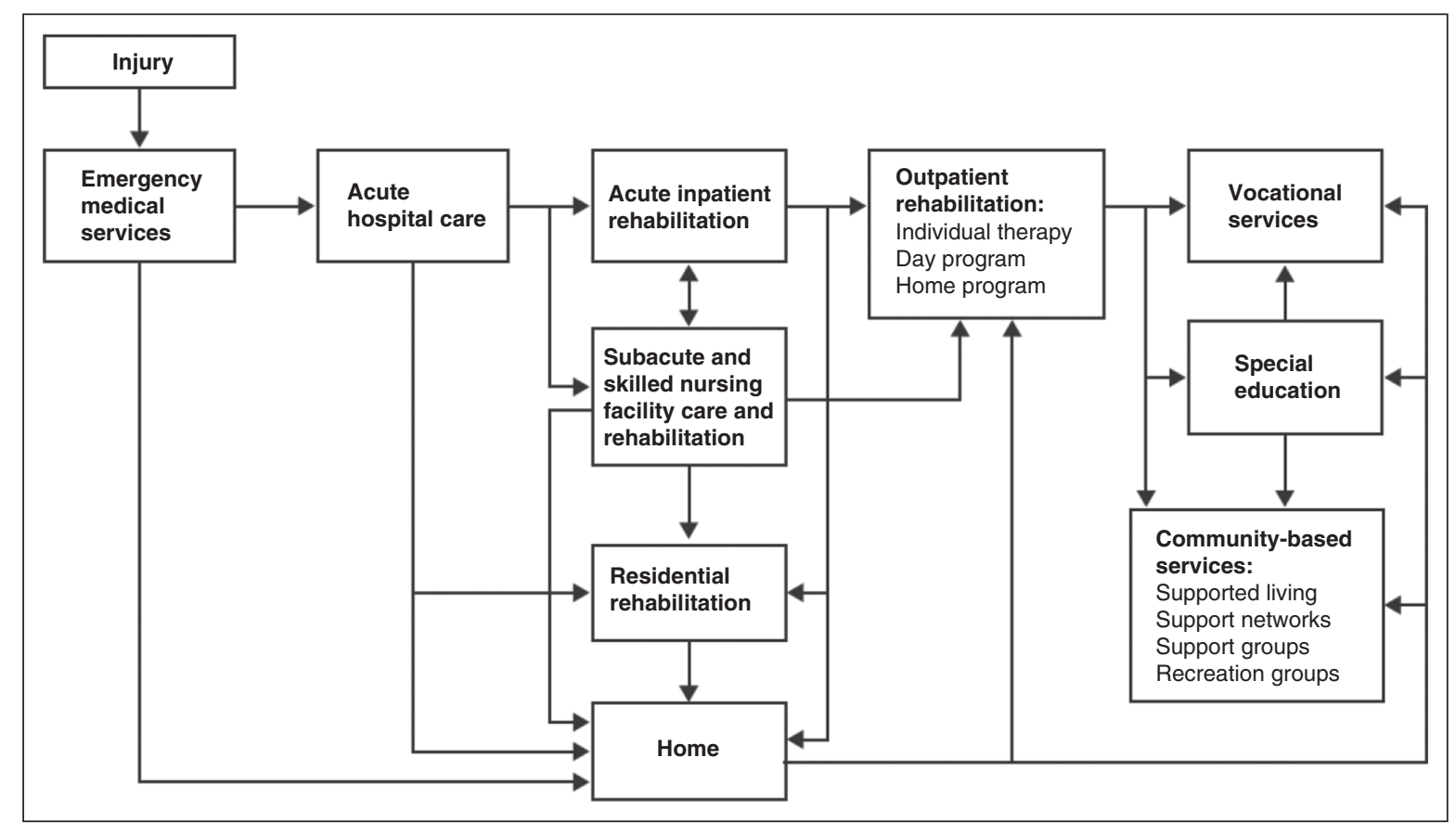

FIGURE 1.1 Usual flow of patients through the clinical continuum of care. Choices of services and direction of flow will be based on severity, stage of recovery, patient's needs, availability of resources, availability of home and community supports, and constraints of the marketplace. 
flow through these services may not be linear and patients may enter or leave the system of care at different points, or reverse directions, based on injury severity, individual needs, and the dictates of the marketplace.

This continuum emphasizes components and flow through the system of care for persons with moderate to severe injury. For those with more mild injuries, most will not require the inpatient components but many will require outpatient services. Accurate diagnosis and early interventions that include information about expected course of recovery, management of symptoms, and return to activities are key for those with milder injuries. Individuals with mild TBI who present for emergency services at level I trauma centers in the United States are more likely to have longer term functional problems requiring interventions than those who do not require emergency services, such as the majority of those who sustain a sports-related concussion. ${ }^{16,35}$ Integrated systems of care are as important for persons with mild TBI as for more severe injuries. Such models have been developed for those with mild TBI, such as the Veterans Health Administration Polytrauma System of Care for returning veterans of the Afghanistan and Iraq conflicts. ${ }^{36}$

\section{Prevention}

The earliest aspect of the care continuum involves public health issues prior to injury occurrence. Injury prevention is an essential part of trauma care systems. The TBI Act of 1996 charged the CDC with the responsibility for prevention, in addition to surveillance, to assess factors that increase risk of TBI and those that are protective. At the international level, the World Health Organization has played a major role in surveillance and prevention. Injury prevention programs generally include three components: programs designed to alter behavior and improve decision-making to increase self-protection; product improvement to minimize chance of injury or protect the individual in an accident; and legislation and public policies that require individuals to follow safety guidelines. Prevention of TBI includes a number of efforts such as reducing alcohol-related injuries, preventing falls, preventing violence, promoting safe practices in sports, promoting helmet and seat belt use, enhancing safe driving practices, and improving vehicle safety.

\section{Prehospital Care and Emergency Medical Services}

The initial response and prehospital management can be a critical determinant of outcome after TBI. Lack of optimal care in the so-called "golden hour" after injury can increase mortality and worsen the level of impairment and disability in survivors. There are wide variations between countries in prehospital care for TBI, related to resources, geography, and differing modes of practice. Low- and middle-income countries have significant challenges in providing prehospital care, ${ }^{37}$ but there are differences even among high-income countries. ${ }^{38}$ Differences in practice vary with respect to time management at the scene versus rapid transfer to hospital, use of air or ground transport, near hospital versus trauma center initial care, and level of medical personnel available in transfers. ${ }^{39,40}$

Since the 1980s, emergency trauma systems have developed throughout the United States and have led to improved survival and recovery. ${ }^{41-43}$ Mortality for those who reach the hospital has been reduced from nearly $50 \%$ to under $18 \% .^{1}$ Regional trauma systems have developed to promote quick evacuation using ground or air transport to level I and II trauma centers from the field, or from level III and IV trauma centers when necessary for more serious injuries. The level I and II trauma centers have full-time intensive care, imaging, neurosurgical, and other trauma subspecialists. The Brain Trauma Foundation Guidelines for Prehospital Management of Traumatic Brain Injury have played a role in improving emergency prehospital care. ${ }^{42,44,45}$ The American College of Surgeons has put out Resources for Optimal Care of the Injured Patient in 1996, updated in 2014, covering all aspects of care, including requirements for rehabilitation services ${ }^{46}$ For mild TBI, provision of accurate diagnosis, adequate patient education, and access to follow-up has improved but is still a challenge for many patients who receive emergency care for mild TBI. ${ }^{47,48}$ A survey of 831 patients in the United States who were evaluated for mild TBI in trauma centers found that only $44 \%$ received follow-up care within 3 months after injury. ${ }^{48}$

\section{Acute Hospital Care}

Patients with TBI who are admitted for acute hospital care range from those who need a brief period of observation to recognize delayed secondary neurological deterioration and neurosurgical complications, to those with mild TBI and comorbidities who require hospital care, to those with more severe brain injury who require intensive medical and neurological management. Transfer to specialist trauma centers, such as level I trauma centers in the United States, is associated with better survival and outcomes. ${ }^{49}$ Acute neurosurgical and intensive care for patients with TBI has improved over the past three decades with lower mortality and better recovery. ${ }^{50,51}$ Evidence-based guidelines for acute TBI care, including the use of intracranial pressure monitoring, have contributed to better outcomes. ${ }^{52-55}$

Rehabilitation assessment and early interventions should take place a short time after admission in the acute hospital setting. Subsequent decisions for rehabilitative care are made as the patient progresses toward medical and surgical stability, when the severity of injury and clinical rehabilitation needs become more apparent. The pathway toward acute inpatient rehabilitation versus outpatient or subacute care is largely based on injury severity and pace of recovery. Generally, patients with severe injuries (e.g., unconsciousness of a day or more or posttraumatic amnesia and confusional states of at least days to weeks or patients with large focal lesions [see Service Delivery in Relation to Natural History of Traumatic Brain Injury]) move to inpatient rehabilitation facilities (IRFs). Constraints related to marketplace issues may affect this decision. For instance, some health care plans in the United States will not support admission to IRFs if a patient has few traditional physical rehabilitation needs (e.g., needs little or no help ambulating) even if the patient has profound cognitive and behavioral disturbances related to the injury. Patients with less severe injuries generally return home and may need home or outpatient rehabilitation services. A proportion of patients with moderate injury may benefit from at least a brief inpatient rehabilitation stay, depending on their circumstances. 
Patients who are slower to recover, who typically have more prolonged disorders of consciousness, may require extended care in the acute hospital prior to post-acute care. Guidelines suggest that such patients should be transferred to facilities with special expertise in the assessment and care of patients who are unconscious or minimally conscious (usually in IRF with specialized programs for persons with disorders of consciousness), since these patients are vulnerable to secondary complications and may have significant potential for further recovery, albeit at a slower pace. ${ }^{31,56,57}$ Some patients with more severe injuries and prolonged disorders of consciousness are transferred to subacute or skilled nursing facility (SNF) care instead of IRF. In many systems, such persons may be lost to the follow-up with clinicians who have expertise in caring for patients with very severe TBI and disorders of consciousness.

\section{Acute Inpatient Rehabilitation: Inpatient Rehabilitation Facilities and Long-Term Acute Care Hospitals}

Acute inpatient rehabilitation may occur in general rehabilitation units or in dedicated brain injury units that are within acute care facilities or part of freestanding post-acute hospitals (usually either an IRF or a long-term acute care hospital [LTACH or LTCH]). LTACH admission is usually targeted for those patients who have higher levels of medical needs with an anticipated longer course of treatment, including rehabilitation. Many LTACHs offer rehabilitation services at a similar intensity and organization as IRFs.

In the United States, admission criteria to IRFs involve: (a) an intensity of medical and nursing care needs that requires full-time physician and rehabilitation specialist monitoring and specialized rehabilitative nursing expertise; (b) functional deficits that would benefit from higher level of rehabilitation treatment intensity (in the United States designated at a minimum duration of 3 hours a day). Patients are best served in programs dedicated to brain injury care or those with a significant proportion of staff with expertise in managing brain injury. Rehabilitation teams usually include case managers, as well as physical, occupational, and speech therapy staff; rehabilitation nurses; nursing assistants; psychologists; neuropsychologists; rehabilitation physicians (usually physiatrist, rehabilitation neurologist, or neuropsychiatrist); primary care physicians; and a variety of other consultant medical specialists. Other disciplines such as social workers, rehabilitation technicians, therapy assistants, behavior specialists, recreation therapists, other subspecialty therapists, chaplains, and attorneys may also contribute to care. Expertise in managing behavioral problems and assuring patient, family, and staff safety is important since patients in posttraumatic confusional states (PTCSs), frequently with associated behavioral dysregulation, are usually managed at this level of care (see Natural History of Diffuse Injury). For patients admitted with lower levels of consciousness (vegetative state/unresponsive wakefulness syndrome or minimally conscious state), there should be team members with specialized training and expertise in managing the complex needs of this population, including protocols for diagnosis, prognosis, and clinical care. ${ }^{31}$ Family education to familiarize them with the problems and needs of persons with brain injury is essential at the IRF level of care, especially for those who will transition home from acute inpatient rehabilitation.

The decision regarding the next level of care depends on the patient's medical stability, level of dependency, safety, and whether the person's care needs can be adequately met at home or requires further care in a facility. Patients with severe TBI typically still require some supervision and, perhaps, physical assistance for self-care and mobility when they are ready to be discharged from acute inpatient rehabilitation.

Average length of stay in IRF level of care for patients with TBI in the United States has generally been decreasing, largely related to payer constraints, including the Medicare IRF prospective payment system instituted in 2002. ${ }^{58}$ The cost-efficiency and lifetime cost savings of over 3,500 patients who received specialist inpatient rehabilitation services following severe TBI were demonstrated in a study of over 3,000 patients in the United Kingdom. ${ }^{59}$ Such a study of the cost-effectiveness of IRF and other levels of post-acute care of individuals with TBI in the United States is more challenging and yet to be completed.

\section{Subacute and Skilled Nursing Facility Rehabilitation}

In the United States, patients with TBI are usually admitted to this level of care from acute hospital care or IRF. Therapies are provided at a lower level of intensity than in acute inpatient rehabilitation, and the level of medical monitoring is less frequent and less specialized than acute inpatient rehabilitation. There are a few programs at this level that specialize in neurorehabilitation, and it is certainly preferable if this level of care occurs in programs with personnel who have some expertise in brain injury management. Specialized neurobehavioral treatment units in SNFs are occasionally available in some areas for patients with more persistent behavioral regulation problems. The availability of specialized subacute and SNF facilities may be limited because of market constraints. Care for the needs of TBI patients in these settings may be costly, exceeding the usual reimbursement standards for this level of care. Alternative funding sources or variance in reimbursement standards may be necessary to maintain more specialized subacute or SNF care. Often SNF level rehabilitation care takes place in more general facilities, and frequently younger patients with TBI are in the minority among an older group of patients with other disorders, such as dementia. Lengths of stay at this level of care vary but usually last one or more months; a minority of patients transition to unskilled residential levels of care at the same facilities. A large proportion of patients transition home and may go on to outpatient rehabilitation or other outpatient services.

\section{Outpatient Rehabilitation}

Outpatient rehabilitation can take on a number of different forms. Outpatient rehabilitation may occur at home or in an outpatient rehabilitation facility. Patients sometimes begin with home-based rehabilitation and then continue care in an outpatient facility. It may consist of individual therapies involving physical, occupational, and speech therapists. There may be other available services including psychology, 
neuropsychology, and therapeutic recreation. There may be a team-oriented approach led by a case manager, and outpatient facilities may provide other coordinated activities such as group treatments. Typically, rehabilitation at the outpatient level is a somewhat less coordinated team approach than team management at an IRF, and therapists often provide care more autonomously. This type of care may occur in the setting of the home through a visiting nurse or other agencies, on the premises of an acute hospital, in a rehabilitation hospital, or in a distinct outpatient rehabilitation facility.

A more coordinated form of outpatient rehabilitation may take place in a day program, with a full array of therapies, group treatments and group activities, case management, and regular team meetings to set goals and review progress. These programs are often in naturalistic, community settings and take advantage of this location to set up activities to foster community re-entry treatment goals. More holistic programs may include a psychotherapeutic milieu associated with the therapy programming. Holistic rehabilitation models have demonstrated greater effectiveness than traditional multidisciplinary outpatient rehabilitation models for persons with TBI. ${ }^{60}$

The length and intensity of treatment should be determined by the patient's needs but is often constrained by payers, public and private. Health insurance contract limitations and public funding limitations can lead to outright denials of rehabilitation services or reduced duration of care and range of covered services.

\section{Community-Based Services}

Following outpatient rehabilitation, additional community-based services may be provided for promoting ongoing needs for supervision and assistance; improving independence and participation in activities; returning to school or work; resuming other social roles; improving behavior and social interaction; and providing psychosocial supports.

\section{Residential Rehabilitation}

Supervised group residences may provide services at various stages after injury. These programs may offer individual therapies and group therapies, as well as resources to foster independent living skills. Residential programs may be aimed at patients just discharged from acute inpatient rehabilitation or for those later in the process of recovery who require a more structured supervised setting and cannot be in their own home setting. These residences may offer parttime nursing services and rarely provide physician services. Those states in the United States with more generous auto insurance benefits tend to have more extensive residential programs. Staffing includes personnel who supervise and assist residents and may include a mix of therapists and other professional disciplines, who may be on staff or outside contractors. Some residents may attend supervised day programs for therapeutic, recreational, and social activities. Individuals may remain in residential programs long term or may progress to return home or move to other long-term living arrangements (see Other Community-Based Services).

\section{Vocational Services}

For persons with TBI, return to work can be an important long-term rehabilitation goal and measure of treatment success. Return to some sort of productive activity is an essential part of societal reintegration and life satisfaction after brain injury and an important part of the continuum of care. In the United States, the states receive federal money to operate vocational rehabilitation programs to provide vocational rehabilitation services to individuals with disabilities. Services support reeducation, training, and worksite-related support services. Even those with severe injuries, who may not qualify for regular marketplace jobs, are eligible for services under this mandate. Supported employment has become one of the important vocational rehabilitation strategies for getting persons with disabilities back to employment in regular work sites. These services are most successful when coordinated with outpatient rehabilitative care and assessments. Many of these programs have been underfunded, and it has been a challenge to provide intensive ongoing supports that are often necessary to keep persons with persisting problems after TBI employed. Many states have adopted innovative programs to extend funding using resources such as Medicaid waivers to improve services and employment retention. ${ }^{61}$

\section{Special Education}

Education services are a necessary component of the continuum of care for children and adolescents with TBI. TBI became a part of the federal Individuals with Disability Education Act in 1990. This federal law mandates that the education needs of school-age children with TBI, among other disabilities, will be provided by the public schools by mainstreaming in the classroom, in special classrooms, or in specialized schools for students with cognitive or behavioral needs. Programming must include any necessary rehabilitation services. Services should be planned and monitored using an individualized educational program. Students often transition from inpatient or outpatient rehabilitation to school-based services, sometimes beginning with home tutoring. Ylvisaker and colleagues have made a number of recommendations for assessment, intervention, student support, educator training, family support, and system flexibility to better serve the particular educational and rehabilitative needs of students after TBI. ${ }^{62}$

\section{Other Community-Based Services}

Persons with TBI may require other ongoing care and supports after formal rehabilitative care has ended. These home- and community-based services are more fragmented and less readily available. Patients who are unable to live independently and are not relying on home supervision by family or friends require supported living environments. Previously, since Medicaid has been the primary funder of long-term care, this meant placement in nursing homes, usually a poor alternative for younger persons with TBI. A growing number of states with Medicaid waiver programs have moved to provide supported living services in the community using such models as supervised group homes, foster homes, and personal care attendants. ${ }^{63,64}$ A number of other models have been developed.

Community support networks and support groups for persons with TBI and their families are important resources. One such support network, the clubhouse model, adapted for persons with TBI in the 1980s from the psychiatric community, provides a setting for members and volunteers to 
participate in social, recreational, and work-related activities. Such models provide a cost-effective method to promote practical, functional living skills. Support groups for persons with TBI and their families are often sponsored by state chapters of the Brain Injury Association of America.

Other necessary community services include provisions for transportation for those who are unable to drive or ride public transportation. Respite care to provide timeoff for full-time caretakers of persons with severe disability after TBI is another important need. Legal services, financial and estate planning, recreational activities, mental health services, and treatment of substance abuse should also be considered part of the community-based system of care for people with TBI.

\section{Case Management}

Fragmentation and lack of coordination of care are major problems in establishing proper services for individuals with TBI. Case managers within institutions and in the community play an essential role in coordinating services. Case managers collaborate with patients, families, providers, and payers to assess, plan, implement, coordinate, and monitor services in order to meet an individual's needs and promote favorable outcomes in a cost-effective manner. In addition to coordinating care within the TBI system, case managers coordinate treatment for other problems such as chronic pain, mental health, and other medical specialty areas. Case managers and life-care planners may develop proposals outlining the anticipated lifelong care needs of persons with TBI. The primary role of case managers is to advocate for their clients and their caretakers, but their role may be funded by a variety of sources, including providers, payers (public, private, workers' compensation), government agencies, and private pay. Case management services are often lacking after early rehabilitation in an IRF, and service coordination is frequently a major challenge for patients and families.

\section{SERVICE DELIVERY IN RELATION TO NATURAL HISTORY OF TRAUMATIC BRAIN INJURY}

TBI is complex and variable in its pathophysiological and clinical effects. Treatment along the continuum of care, from acute to post-acute to longer term care, should be individualized based on a patient's particular needs. Guidelines can be helpful in directing care, but they often rely on more simplistic approaches to categorizing the injury and clinical problems that challenge the clinician's ability to adequately individualize treatment. Recent advances in TBI biomarkers, including structural and functional neuroimaging, genomics, and proteomics, and the ability to integrate large amounts of data from different sources, offer promise in better characterization and more targeted and individualized approaches, especially during the acute and post-acute phases of care.

During the post-acute period after TBI and beyond, accurate diagnosis and an appreciation of the natural history of TBI are useful in formulating rehabilitation treatment plans and assuring appropriateness of services along the continuum of care. This effort involves assessing a person's brain injury in the context of pathophysiological damage, associated clinical neurobehavioral syndromes, stage of recovery, and anticipated course of recovery, based on knowledge of brain-behavior relationships and natural history. ${ }^{65}$ This formulation must also consider interaction with other factors such as age, psychosocial issues, associated injuries, premorbid problems, comorbidities, and later complications. ${ }^{66}$ This understanding helps in determining injury severity, prognosis, and anticipated natural history. Assessing where the patient is along the path of recovery and projecting expectations for subsequent recovery should inform treatment planning with respect to treatment setting, strategies, goals, and duration. Such assessments should contribute to length of stay planning for inpatient and outpatient rehabilitation care settings. Rehabilitation intervention strategies may focus on restorative, compensatory, adaptive, or some combination of approaches. Consideration of diagnosis, prognosis, timing of interventions, and the potential for neural plasticity and repair may affect the choice of optimal strategies. Treatment formulations may vary depending on time post-injury. More intensive restorative rehabilitation techniques should be emphasized where evidence supports efficacy, especially earlier in recovery, during sensitive periods when the central nervous system may be more amenable to reorganization. Appreciation of natural history helps identify problems with worse prognosis for recovery that may suggest emphasis on more compensatory and adaptive approaches. These assessments may also help avoid unnecessary rehabilitative interventions for problems that may be expected to resolve as part of the natural course of recovery (e.g., amnesia or agitated behavioral dyscontrol during the PTCS). An understanding of natural history also helps determine when clinical syndromes do not fit the expected path of recovery, suggesting possible secondary neurological complications (e.g., hydrocephalus, chronic subdural hematomas), the influence of noninjury factors (medical, iatrogenic, psychogenic, or secondary gain), or misdiagnosis of injury type and severity.

The pathophysiology of TBI is highly complex with widely varying patterns of damage and severity. A simplified but useful conceptualization considers the TBI pathology according to primary and secondary injury, as well as focal and diffuse neuropathological events. The primary injury is the damage that occurs at the time of injury and the secondary injury is the damage occurring as a result of the delayed host responses to the primary injury, such as brain swelling, loss of vasoregulation, excitotoxicity, metabolic disturbance, and immunological reactions. The critical pathophysiological factors that determine the clinical manifestations are the type, distribution, severity, and location of these combined neuropathological events after brain injury. Although focal and diffuse pathological processes are often intermingled and have common secondary injury consequences, it can be useful to consider their separate contributions for the purposes of clinical diagnosis. Precise clinical pathophysiological diagnosis is challenging, especially with respect to diffuse and secondary injuries, for which there are as yet limited clinical diagnostic probes in regular clinical use. Blood biomarkers, genetic analysis, and physiological and newer neuroimaging techniques hold promise as clinical diagnostic biomarkers of primary and secondary injury. ${ }^{6}$ 


\section{Natural History of Diffuse Injury}

Diffuse axonal injury represents the main diffuse pathological process, but it is associated with a host of secondary pathophysiological phenomena. The natural history of diffuse injury is characterized by a recognizable pattern of stages of recovery that occur across the wide spectrum of severity. Injury severity largely determines the duration of recovery stages and levels of impairment at each stage of recovery. Structural and functional imaging studies that examine the extent of diffuse damage with respect to white matter integrity and connectivity demonstrate significant relationships with duration of posttraumatic amnesia (PTA), attention, memory, executive functioning, and speed of processing. ${ }^{67-69}$

These stages can be combined into three principal phases of recovery from the acute to chronic stages: (a) impaired consciousness (loss of consciousness [LOC]), (b) PTCS (closely linked to PTA), and (c) post-confusional restoration of cognitive function. These form the basis for the main indices of clinical severity for TBI, and these indices can help project rough approximations for time course of recovery and probabilities for outcome. ${ }^{70-74}$ These three phases of recovery appear to be proportionally related in patients with diffuse injury; each subsequent phase is typically several fold longer than the previous one. ${ }^{70,73}$ Their proportionality in patients with diffuse injury, although variable, can contribute to predicting time course of recovery. Predicting the duration of PTCS (or PTA) may aid rehabilitative treatment planning with respect to length of stay decisions, treatment choices for confusional agitation, and other treatment issues at this stage of recovery. The severity of PTCS and presence of certain components of confusion, such as psychotic-like features, have predictive value for rehabilitation outcomes and employability. ${ }^{75-77}$

Patients with the least severe diffuse injuries (mild TBI, concussion) evolve through LOC (if complete loss of consciousness occurs at all) in seconds to minutes and through PTCS (PTA) usually in minutes to hours, followed by a post-confusional phase typically lasting days to weeks. In mild TBI, the transition through the earliest stages may be brief, unwitnessed, and difficult to document. Patients with severe TBI may require days to weeks to evolve through LOC, weeks to months to resolve PTCS (PTA), and months to years to evolve through the post-confusional residual recovery phase. The course of recovery after severe TBI can be among the longest observed after neurological damage. Dynamic changes in neuropsychological measures and level of functioning have been observed as long as 5 to 10 years post-injury. ${ }^{78-82}$ Some patients with very severe injuries may stall in recovery at some stage in this process (e.g., chronic vegetative state ${ }^{83,84}$ or minimally conscious state $\left.{ }^{85,86}\right)$.

This pattern of recovery has been delineated in stages according to various schemas. The most widely used is the Rancho Los Amigos levels of cognitive functioning ${ }^{87}$ (see Table 1.1). Another schema, first proposed by Alexander ${ }^{88}$ and further modified (sometimes referred to as the Braintree scale), ${ }^{56,65,89}$ tracks similar stages using more familiar neurological nomenclature, with established diagnostic criteria $^{90,91}$ (see Table 1.2). As patients progress through these stages, the principal defining cognitive limitations evolve from deficits in arousal and consciousness, to basic attention and anterograde amnesia, to higher level attention,
TABLE 1.1 Rancho Los Amigos Levels of Cognitive Functioning After TBI
I. No response
II. Generalized responses
III. Localized responses
IV. Confused-agitated
V. Confused-inappropriate
VI. Confused-appropriate
VII. Automatic-appropriate
VIII. Purposeful and appropriate

$\mathrm{TBI}$, traumatic brain injury.

Source: From Hagen C, Malkmus D, Durham P. Levels of Cognitive Functioning. Ranchos Los Amigos Hospital; 1972.

memory, executive functioning, processing speed, insight, and social awareness. ${ }^{92}$ Not all of the stages described will be recognized in all patients. Patients with more severe injuries and more prolonged progression of recovery are more likely to demonstrate progression through all the levels described in these schemas. Patients with less severe injuries or injuries with predominantly focal injury may not demonstrate recognizable transitions through all of the stages described. ${ }^{91}$

The first stage of recovery is coma, a state of unconsciousness without spontaneous eye opening. This corresponds to Rancho level I. Patients with diffuse axonal injury are unconscious at the outset, without lucid interval. The depth of coma in the time period shortly after injury, as measured by the Glasgow Coma Scale (GCS), is one of the common markers of injury severity and prognosis.

Almost all persons with severe TBI, who survive, resume spontaneous eye opening and sleep/wake cycles by 4 weeks post-injury. If eye opening resumes while still unconscious, the condition is termed vegetative state, also referred to as unresponsive wakefulness syndrome ${ }^{95}$ or Rancho level II. Almost all patients with some loss of consciousness will be evaluated and treated by emergency medical services. Those with brief alterations of consciousness (e.g., seconds or minutes) may be discharged home. Patients with more prolonged LOC or more complicated injuries (e.g., focal lesions, other injuries) will likely be admitted for acute inpatient care, often beginning in surgical ICUs, usually supervised by neurosurgical or surgical trauma specialists.

Except for the small percentage of very severely injured patients who remain chronically vegetative, evidence of awareness and purposeful behavior resumes. The ability to follow commands is the usual marker of restored consciousness. For patients recovering slowly, initial behavioral evidence of consciousness may be very inconsistent and simple. The first signs of awareness may involve perceptual localizations without any command following or other signs of language capacity. This stage is termed minimally conscious state and corresponds to Rancho level III. ${ }^{85}$ Many patients at this stage will continue in acute medical care settings and some who are slower to recover will transition to rehabilitation facilities, including acute inpatient rehabilitation (IRF 
TABLE 1.2 Braintree Neurological Stages of Recovery From Diffuse TBI (and Corresponding Rancho Los Amigos Scale Levels) [Typical Settings of Care]

1. Coma: unconscious, eyes closed, no sign of wakefulness (Rancho 1) [emergency medical services; acute inpatient hospital]

2. Vegetative state: wakeful unconsciousness; transition marked by beginning spontaneous eye opening and sleep-wake cycles (Rancho 2) [acute hospital]

3. Minimally conscious state: inconsistent, simple purposeful behavior, inconsistent response to commands begin; transition can be documented using CRS-R subscale criteria for $\mathrm{MCS} ;{ }^{93}$ often mute (Rancho 3 ) [acute hospital; acute inpatient rehabilitation facility; subacute rehabilitation]

4. Posttraumatic confusional state: interactive communication and appropriate object use begin; transition can be documented using CRS-R subscale criteria for emergence from MCS; ${ }^{93}$ amnesic (PTA), disoriented, severe basic attentional deficits, fluctuation, hypokinetic or agitated, behavior; later more appropriate goal-directed behavior but with continuing anterograde amnesia (Rancho 4, 5, partly 6) [acute inpatient rehabilitation facility; acute hospital]

5. Post-confusional/emerging independence: marked by resolution of PTCS and PTA; transition can be marked using scales such as the Galveston Orientation and Amnesia Test ${ }^{94}$ and the Confusion Assessment Protocol; ${ }^{76}$ cognitive impairments in higher level attention, memory retrieval and executive functioning; deficits in self-awareness, social awareness, behavioral and emotional regulation; achieving functional independence in daily self-care, improving social interaction; developing independence at home (Rancho 6 and partly 7) [acute inpatient rehabilitation facility; subacute inpatient rehabilitation; outpatient rehabilitation; residential treatment; outpatient day hospital and community re-entry]

6. Social competence/community re-entry: marked by resumption of basic household independence and ability to be left home unsupervised for the better part of a day; developing independence in community, household management skills, and later returning to academic or vocational pursuits; recovering higher level cognitive abilities (divided attention, cognitive speed, executive functioning), self-awareness, social skills; developing effective adaptation and compensation for residual problems (Rancho 7 and 8) [outpatient community re-entry programs; community-based services_vocational; special education; supported living services; mental health services]

CRS-R, Coma Recovery Scale-Revised; MCS, minimally conscious state; PTA, posttraumatic amnesia; PTCS, posttraumatic confusional state; TBI, traumatic brain injury.

or LTACH facilities), subacute rehabilitation, long-term care hospitals, or SNFs.

When purposeful cognition is unequivocally established, basic attention and new learning remain severely impaired, and patients are disoriented. This clinical condition is labeled posttraumatic confusional state and corresponds to Rancho levels IV, V, and part of VI. At this stage, patients are often highly distractible, with poorly regulated fluctuations in behavior. They may rapidly escalate to agitated behavior (Rancho IV). Less often, patients may remain in a state of hypokinetic, withdrawn behavior. Severe anterograde amnesia also defines this stage; patients are disoriented, have little or no moment-to-moment episodic recall, and display severely reduced ability to encode and retain new information, after even a brief delay. This defines the PTA, a condition that is part of the PTCS..$^{92}$ As this stage evolves, patients are better able to focus attention and regulate behavior (Rancho V). The end of this stage is characterized by a significant improvement in focused and sustained attention, reliable orientation, and resumption of continuous day-to-day memory, as well as improved declarative learning. Memory retrieval may still be impaired (Rancho VI).

Patients at this period of recovery are appropriate for care in dedicated TBI units in acute IRFs. Transition to home and outpatient rehabilitation programs should occur toward the end of this period of recovery. Patients who are transitioning slowly, or who still require significant amounts of supervision and assistance that may not be feasible at home, may require continued treatment in a supervised care facility, perhaps at an SNF or a residential treatment facility. Some may transition to an outpatient day program.
The post-confusional stages of recovery are characterized by a gradual improvement in cognitive and behavioral functioning in those with more severe injuries. At these stages, individuals typically display deficits in higher level attention, speed of processing, working memory, memory retrieval, and executive functioning, impairments that continue to evolve. This phase of recovery may be further broken into stages of emerging independence, as patients' cognitive abilities, self-awareness, and insight allow independence in self-care and safe unsupervised activity at home (Rancho level VII), and a stage of social competence and community re-entry, with the ability to manage independently at home for an extended time during the day. At this last stage, individuals can regain capacity for independent functioning in the community or at the higher level demands of school or the workplace (Rancho level VIII). Services at these stages of care include outpatient therapies, day programs, community re-entry programs, residential treatment, and a variety of community-based services.

\section{Natural History of Focal Injury}

Focal cortical contusions, deep cerebral hemorrhages, and extra-axial (subdural and epidural) hemorrhages make up the majority of focal lesions after TBI. The time course of natural history of focal injury resembles that of vascular lesions of other causes, particularly hemorrhagic stroke, but the clinical consequences of focal injury after TBI are characteristic, owing to the predilection of lesions in the anterior and inferior portions of the frontal and temporal lobes. The acute phase involves edema and other early secondary pathophysiological 
phenomena that are maximal over the first few days post-injury. The resulting effects may include confusion and can cause decreased arousal and unconsciousness, especially if mass effect compromises diencephalic and mesencephalic structures. Otherwise, primary focal pathology is not necessarily associated with complete loss of consciousness.

As edema and other secondary effects wane over the first 1 to 3 weeks, more specific localizing effects of focal damage may become more apparent. Recovery during this subacute phase is maximal over the first 3 months, but improvement may continue at a slower rate over many months. The size and depth of focal lesions, their laterality, and the potential for reorganization within the neural networks affected by the damage in large part determines the time course and outcome.

Damage to limbic neocortical and heteromodal areas of the frontal and temporal lobes determines the usual effects of focal TBI on cognitive and behavioral functioning. The residual syndromes of prefrontal lesions include alterations in affect and behavior (e.g., disinhibition or apathy); impairment in attention, working memory and memory retrieval; and executive functioning. Lesions in anterior and inferior temporal areas may also contribute to affective and behavioral disturbances. Larger lesions extending to medial temporal areas may produce specific impairments in memory encoding and retrieval (amnesia). Other localizing temporal syndromes involve extension of lesions into auditory association areas (e.g., aphasia, with left-hemisphere lesions) and visual association areas (e.g., visual agnosias, especially with bilateral lesions). The localizing effects of focal lesions can persist and should be considered when individualized rehabilitation plans and goals are formulated during acute IRF and outpatient rehabilitation care. ${ }^{96,97}$

The clinical syndromes associated with focal lesions are often embedded in the evolving effects of diffuse injury, if both types of injury are combined. Particularly with more severe diffuse injuries, overall outcome is driven largely by the effects of diffuse rather than focal injury. ${ }^{98}$ In patients with mild to moderate diffuse injury, large focal lesions may have more influence on recovery. ${ }^{99-101}$ Characterization of the localizing syndromes associated with focal lesions may be difficult until unmasked after resolution of posttraumatic confusion. Further, the clinical syndromes associated with focal damage may go beyond that expected with a focal lesion on structural neuroimaging because of more widespread functional network disruption and distal secondary damage. Another difficulty in isolating the effects of focal lesions is that neurobehavioral syndromes may be identical to those related to diffuse injury (e.g., dysexecutive syndrome; behavioral dysregulation) since these same areas, especially their axonal projections, are affected by diffuse pathology ${ }^{102}$ Although problems are similar, recovery and prognosis may be different. For instance, features of the frontal lobe syndrome may be more persistent in patients with frontal focal cortical contusions. ${ }^{103,104}$ Levin et al. ${ }^{105}$ observed that although other aspects of recovery were similar, unilateral frontal lesions adversely affect psychosocial outcome in children with TBI compared to those without focal frontal lesions. These aspects of diagnosis and prognosis related to focal lesions should also help inform rehabilitation planning. For example, behavioral regulation problems related to bilateral frontal and temporal focal lesions might be more persistent and thus demand more active early intervention and treatment planning over a longer horizon than similar problems that might occur after diffuse injury, which might be expected to resolve more successfully as the stages of recovery evolve.

A more complete picture of the relationship between clinical effects, natural history, and pathophysiology-diffuse, focal, and secondary-requires an overall assessment of pre-injury personal factors (e.g., age, education, premorbid problems, psychosocial issues), injury mechanism, early clinical markers (e.g., GCS, duration of unconsciousness and PTA), neuroimaging, secondary complications, and clinical assessment, including neuropsychological profile. Investigations have demonstrated the benefits of combining multiple structural imaging, functional imaging, and clinical assessment modalities to enhance understanding of brain-behavior relationships in TBI. ${ }^{106}$ As newer neuroimaging and other technologies come on line for clinical use, understanding of pathophysiological-clinical relationships and predictions of natural history and outcome will improve. Large data sets such as International Mission for Prognosis and Analysis of Clinical Trials in TBI and IMPACT (International Mission for Prognosis and Analysis of Clinical Trials in TBI) and CRASH (Corticosteroid Randomization After Significant Head Injury) provided improved prognostic models for outcome prediction. ${ }^{107,108}$ Recent large collaborative efforts, such as Transforming Research and Clinical Knowledge in Traumatic Brain Injury and Collaborative European NeuroTrauma Effectiveness Research in Traumatic Brain Injury, have demonstrated great promise to improve characterization of injuries, prognosis, best practices, and use of precision medicine to individualize treatment. These initiatives should greatly improve accuracy of diagnosis, prognosis, and treatment choices for better outcomes and effective care coordination along the path of recovery. ${ }^{109,110}$

\section{CONCLUSION}

Systems of care for persons with TBI have evolved in the United States and worldwide since the 1970s but have not done so in a geographically symmetrical fashion. Components of ideal systems of care include prevention, emergency medical services, acute hospital care, acute inpatient rehabilitation, subacute/skilled nursing facility, outpatient rehabilitation, residential rehabilitation, avocational and vocational services, special education, community-based services, long-term care, and case management. Limitations in public and private insurance payer support and provider resources have been major challenges to the availability of a continuum of care and services for persons with TBI.

An understanding of the natural history of TBI in the context of the severity and types of brain damage can inform treatment decisions and aids in managing services for patients along the continuum of care to assure more effective and efficient use of resources.

Further research is needed on effectiveness and efficiency of the components and ingredients of TBI systems of care, including how they impact functional outcome and quality of life. Additionally, continued research is needed to optimize our understanding of the natural history of recovery from TBI and interventions that impact recovery and outcomes. 


\section{KEY CLINICAL POINTS}

1. The provision of systems of care for persons with TBI needs to account for: the high incidence and prevalence of TBI; potential long-term course of recovery and lifelong effects; problems that often begin at an earlier stage of life and that affect patients, families, and others in a patient's life; commonly associated preexisting conditions and psychosocial problems, such as substance abuse and learning disability; typical effects on cognition and behavior; and the wide variety in range of severity, types of brain damage, clinical effects, and associated problems.

2. Systems of care for TBI must involve coordination of numerous services, involving several disciplines, over the course of recovery.

3. Several marketplace factors constrain the availability of components of these systems of care, most notably cost, payer support, and availability of resources. These constraints become progressively restrictive for services and supports beyond the acute treatment period. There is considerable variability in availability of resources among countries and in different regions within countries.

4. The pathophysiology of TBI is complex involving combinations of diffuse, focal, and secondary brain damage. The natural history of TBI, particularly with diffuse injury, is characterized by a recognizable pattern across a range of severities involving impaired consciousness, posttraumatic confusion, and postconfusional restoration of cognitive function. Focal lesions may add to the clinical consequences and affect outcome based on their disruption of neural networks, typically prefrontal and temporal lobe cognitive, emotional, and behavioral networks.

5. As newer biomarkers, including advanced imaging and other diagnostic technologies, become clinical tools for assessment, relationships and predictions regarding brain damage, clinical consequences, natural history, and prognosis will improve. Ongoing efforts at high-quality research to determine what interventions are most effective, for whom, and at what stages of recovery will be essential to refine best clinical practices along the continuum of care.

\section{KEY REFERENCES}

Only key references appear in the print edition. The full reference list appears in the digital product found on http:/ / connect.springerpub .com/content/book/978-0-8261-4305-1/part/part01/chapter/ch01

6. Maas AIR, Menon DK, Adelson PD, et al. Traumatic brain injury: integrated approaches to improve prevention, clinical care, and research. Lancet Neurol. 2017;16:987-1048. doi:10.1016/ S1474-4422(17)30371-X

15. Cicerone KD, Goldin Y, Ganci K, et al. Evidence-based cognitive rehabilitation: systematic review of the literature from 2009 through 2014. Arch Phys Med Rehabil. 2019;100:1515-1533. doi:10.1016/j.apmr.2019.02.011

24. Cope DN, Mayer NH, Cervelli L. Development of systems of care for persons with traumatic brain injury. J Head Trauma Rehabil. 2005;20:128-142. doi:10.1097/00001199-200503000-00002

31. Giacino JT, Whyte J, Nakase-Richardson R, et al. Minimum competency recommendations for programs that provide rehabilitation services for persons with disorders of consciousness: a position statement of the American Congress of Rehabilitation Medicine and the National Institute on Disability, Independent Living and Rehabilitation Research Traumatic Brain Injury Model Systems. Arch Phys Med Rehabil. 2020;101:1072-1089. doi:10.1016/j.apmr.2020.01.013

45. Spaite DW, Bobrow BJ, Keim SM, et al. Association of statewide implementation of the prehospital traumatic brain injury treatment guidelines with patient survival following traumatic brain injury: the Excellence in Prehospital Injury Care (EPIC) Study. JAMA Surg. 2019;154:e191152. doi:10.1001/jamasurg.2019.1152

57. Giacino JT, Katz DI, Schiff ND, et al. Practice guideline update recommendations summary: disorders of consciousness: Report of the Guideline Development, Dissemination, and Implementation Subcommittee of the American Academy of Neurology; the American Congress of Rehabilitation Medicine; and the National Institute on Disability, Independent Living, and Rehabilitation Research. Neurology. 2018;91:450-460. doi:10.1212/WNL.0000000000005926

65. Povlishock JT, Katz DI. Update of neuropathology and neurological recovery after traumatic brain injury. J Head Trauma Rehabil. 2005;20:76-94. doi:10.1097/00001199-200501000-00008

66. Corrigan JD, Zheng T, Pinto SM, et al. Effect of preexisting and co-occurring comorbid conditions on recovery in the 5 years after rehabilitation for traumatic brain injury. $J$ Head Trauma Rehabil. 2020;35:E288-E298. doi:10.1097/HTR .0000000000000521 


\section{For Digital Content Only}

1. Faul M, Wald MM, Coronado VG. Traumatic Brain Injury in the United States: Emergency Department Visits, Hospitalizations and Deaths 2002-2006. Centers for Disease Control and Prevention, National Center for Injury Prevention and Control; 2010.

2. Taylor CA, Bell JM, Breiding MJ, Xu L. Traumatic Brain Injury-Related Emergency Department Visits, Hospitalizations, and Deaths United States, 2007 and 2013. MMWR Surveill Summ. 2017;66:1-16. doi:10.15585/mmwr.ss6609a1

3. Frost RB, Farrer TJ, Primosch M, Hedges DW. Prevalence of traumatic brain injury in the general adult population: a meta-analysis. Neuroepidemiology. 2013;40:154-159. doi:10.1159/000343275

4. Whiteneck GG, Cuthbert JP, Corrigan JD, Bogner JA. Prevalence of self-reported lifetime history of traumatic brain injury and associated disability: a statewide population-based survey. J Head Trauma Rehabil. 2016;31:E55-E62. doi:10.1097/HTR.0000000000000140

5. Zaloshnja E, Miller T, Langlois JA, Selassie AW. Prevalence of long-term disability from traumatic brain injury in the civilian population of the United States, 2005. J Head Trauma Rehabil. 2008;23:394-400. doi:10.1097/01.HTR.0000341435.52004.ac

6. Maas AIR, Menon DK, Adelson PD, et al. Traumatic brain injury: integrated approaches to improve prevention, clinical care, and research. Lancet Neurol. 2017;16:987-1048. doi:10.1016/S1474-4422(17)30371-X

7. Langlois JA, Marr A, Mitchko J, Johnson RL. Tracking the silent epidemic and educating the public: CDC's traumatic brain injury-associated activities under the TBI Act of 1996 and the Children's Health Act of 2000. J Head Trauma Rehabil. 2005;20:196-204. doi:10.1097/00001199-200505000-00003

8. Coronado VG, Thomas KE, Sattin RW, Johnson RL. The CDC traumatic brain injury surveillance system: characteristics of persons aged 65 years and older hospitalized with a TBI. J Head Trauma Rehabil. 2005;20:215-228. doi:10.1097/00001199-200505000-00005

9. Mushkudiani NA, Engel DC, Steyerberg EW, et al. Prognostic value of demographic characteristics in traumatic brain injury: results from the IMPACT study. J Neurotrauma. 2007;24:259-269. doi:10.1089/neu.2006.0028

10. Baldwin GT, Breiding MJ, Dawn Comstock R. Epidemiology of sports concussion in the United States. Handb Clin Neurol. 2018;158:6374. doi:10.1016/B978-0-444-63954-7.00007-0

11. Timonen M, Miettunen J, Hakko H, et al. The association of preceding traumatic brain injury with mental disorders, alcoholism and criminality: the Northern Finland 1966 Birth Cohort Study. Psychiatry Res. 2002;113:217-226. doi:10.1016/S0165-1781(02)00269-X

12. Hughes N, Williams WH, Chitsabesan P, et al. The prevalence of traumatic brain injury among young offenders in custody: a systematic review. J Head Trauma Rehabil. 2015;30:94-105. doi:10.1097/HTR.0000000000000124

13. Cicerone KD, Dahlberg C, Kalmar K, et al. Evidence-based cognitive rehabilitation: recommendations for clinical practice. Arch Phys Med Rehabil. 2000;81:1596-1615. doi:10.1053/apmr.2000.19240

14. Cicerone KD, Dahlberg C, Malec JF, et al. Evidence-based cognitive rehabilitation: updated review of the literature from 1998 through 2002. Arch Phys Med Rehabil. 2005;86:1681-1692. doi:10.1016/j.apmr.2005.03.024

15. Cicerone KD, Goldin Y, Ganci K, et al. Evidence-based cognitive rehabilitation: systematic review of the literature from 2009 through 2014. Arch Phys Med Rehabil. 2019;100:1515-1533. doi:10.1016/j.apmr.2019.02.011

16. Nelson LD, Temkin NR, Dikmen S, et al. Recovery after mild traumatic brain injury in patients presenting to US Level I Trauma Centers: a Transforming Research and Clinical Knowledge in Traumatic Brain Injury (TRACK-TBI) study. JAMA Neurol. 2019;76(9):1049-1059. doi:10.1001/jamaneurol.2019.1313

17. Dwyer B, Katz DI. Postconcussion syndrome. Handb Clin Neurol. 2018;158:163-178. doi:10.1016/B978-0-444-63954-7.00017-3

18. Masel BE, DeWitt DS. Traumatic brain injury: a disease process, not an event. J Neurotrauma. 2010;27:1529-1540. doi:10.1089/neu.2010.1358

19. Xiong C, Hanafy S, Chan V, et al. Comorbidity in adults with traumatic brain injury and all-cause mortality: a systematic review. BMJ Open. 2019;9:e029072. doi:10.1136/bmjopen-2019-029072

20. Wilson L, Stewart W, Dams-O'Connor K, et al. The chronic and evolving neurological consequences of traumatic brain injury. Lancet Neurol. 2017;16:813-825. doi:10.1016/S1474-4422(17)30279-X

21. Gardner RC, Burke JF, Nettiksimmons J, et al. Traumatic brain injury in later life increases risk for Parkinson disease. Ann Neurol. 2015;77:987-995. doi:10.1002/ana.24396

22. McKee AC, Cairns NJ, Dickson DW, et al. The first NINDS/NIBIB consensus meeting to define neuropathological criteria for the diagnosis of chronic traumatic encephalopathy. Acta Neuropathol. 2016;131:75-86. doi:10.1007/s00401-015-1515-z

23. Mez J, Daneshvar DH, Kiernan PT, et al. Clinicopathological evaluation of chronic traumatic encephalopathy in players of American Football. JAMA. 2017;318:360-370. doi:10.1001/jama.2017.8334

24. Cope DN, Mayer NH, Cervelli L. Development of systems of care for persons with traumatic brain injury. J Head Trauma Rehabil. 2005;20:128-142. doi:10.1097/00001199-200503000-00002

25. Ragnarsson KT, Thomas JP, Zasler ND. Model systems of care for individuals with traumatic brain injury. J Head Trauma Rehabil. 1993;8:1-11. doi:10.1097/00001199-199308020-00003

26. Corrigan JD. Conducting statewide needs assessments for persons with traumatic brain injury. J Head Trauma Rehabil. 2001;16:1-19. doi:10.1097/00001199-200102000-00004

27. Rehabilitation of persons with traumatic brain injury. NIH Consens Statement. 1998;16(1):1-41.

28. Management of Concussion/mTBI Working Group. VA/DoD Clinical Practice Guideline for Management of Concussion/Mild Traumatic Brain Injury. J Rehabil Res Dev. 2009;46:CP1-CP68. doi:10.1682/JRRD.2009.06.0076

29. Bell KR, Brockway JA, Hart T, et al. Scheduled telephone intervention for traumatic brain injury: a multicenter randomized controlled trial. Arch Phys Med Rehabil. 2011;92:1552-1560. doi:10.1682/JRRD.2009.06.0076

30. Powell JM, Fraser R, Brockway JA, et al. A telehealth approach to caregiver self-management following traumatic brain injury: a randomized controlled trial. J Head Trauma Rehabil. 2016;31:180-190. doi:10.1097/HTR.0000000000000167

31. Giacino JT, Whyte J, Nakase-Richardson R, et al. Minimum competency recommendations for programs that provide rehabilitation services for persons with disorders of consciousness: a position statement of the American Congress of Rehabilitation Medicine and the National Institute on Disability, Independent Living and Rehabilitation Research Traumatic Brain Injury Model Systems. Arch Phys Med Rehabil. 2020;101:1072-1089. doi:10.1016/j.apmr.2020.01.013

32. Hingley S, Ross J. Guidelines for diagnosing and managing paediatric concussion: Ontario Neurotrauma Foundation guideline. Arch Dis Child Educ Pract Ed. 2016;101:58-60. doi:10.1136/archdischild-2014-307252

33. Ontario Neurotrauma Foundation. Guidelines for Concussion/Mild Traumatic Brain Injury \& Persistent Symptoms. 2018. 
34. Lamontagne ME, Gargaro J, Marier-Deschenes P, et al. A survey of perceived implementation gaps for a clinical practice guideline for the rehabilitation of adults with moderate to severe traumatic brain injury. J Head Trauma Rehabil. 2018;33:306-316. doi:10.1097/ HTR.0000000000000430

35. Stein MB, Jain S, Giacino JT, et al. Risk of posttraumatic stress disorder and major depression in civilian patients after mild traumatic brain injury: a TRACK-TBI study. JAMA Psychiatry. 2019;76:249-258. doi:10.1001/jamapsychiatry.2018.4288

36. Belanger HG, Uomoto JM, Vanderploeg RD. The Veterans Health Administration's (VHA's) Polytrauma System of Care for mild traumatic brain injury: costs, benefits, and controversies. J Head Trauma Rehabil. 2009;24:4-13. doi:10.1097/HTR.0b013e3181957032

37. Roudsari BS, Nathens AB, Arreola-Risa C, et al. Emergency Medical Service (EMS) systems in developed and developing countries. Injury. 2007;38:1001-1013. doi:10.1016/j.injury.2007.04.008

38. Timm A, Maegele M, Lefering R, et al. Pre-hospital rescue times and actions in severe trauma. A comparison between two trauma systems: Germany and the Netherlands. Injury. 2014;45(Suppl 3):S43-S52. doi:10.1016/j.injury.2014.08.017

39. Williams T, Finn J, Fatovich D, Jacobs I. Outcomes of different health care contexts for direct transport to a trauma center versus initial secondary center care: a systematic review and meta-analysis. Prehosp Emerg Care. 2013;17:442-457. doi:10.3109/10903127.2013.804137

40. Cnossen MC, Scholten AC, Lingsma HF, et al. Adherence to guidelines in adult patients with traumatic brain injury: a living systematic review. J Neurotrauma. Published online August 25, 2016. doi:10.1089/neu.2015.4121

41. Rudehill A, Bellander BM, Weitzberg E, et al. Outcome of traumatic brain injuries in 1,508 patients: impact of prehospital care. J Neurotrauma. 2002;19:855-868. doi:10.1089/08977150260190447

42. Watts DD, Hanfling D, Waller MA, et al. An evaluation of the use of guidelines in prehospital management of brain injury. Prehosp Emerg Care. 2004;8:254-261. doi:10.1016/j.prehos.2004.02.001

43. Zink BJ. Traumatic brain injury outcome: concepts for emergency care. Ann Emerg Med. 2001;37:318-332. doi:10.1067/mem.2001.113505

44. Badjatia N, Carney N, Crocco TJ, et al. Guidelines for prehospital management of traumatic brain injury 2nd edition. Prehosp Emerg Care. 2008;12(Suppl 1):S1-S52. doi:10.1080/10903120701732052

45. Spaite DW, Bobrow BJ, Keim SM, et al. Association of statewide implementation of the prehospital traumatic brain injury treatment guidelines with patient survival following traumatic brain injury: the Excellence in Prehospital Injury Care (EPIC) Study. JAMA Surg. 2019;154:e191152. doi:10.1001/jamasurg.2019.1152

46. Eastman AB. Resources for optimal care of the injured patient-1993. Bull Am Coll Surg. 1994;79:21-27.

47. von Wild K, Terwey S. Diagnostic confusion in mild traumatic brain injury (MTBI). Lessons from clinical practice and EFNS--inquiry. European Federation of Neurological Societies. Brain Inj. 2001;15:273-277. doi:10.1080/026990501300005712

48. Seabury SA, Gaudette E, Goldman DP, et al. Assessment of follow-up care after emergency department presentation for mild traumatic brain injury and concussion: results from the TRACK-TBI Study. JAMA Netw Open. 2018;1:e180210. doi:10.1001/ jamanetworkopen.2018.0211

49. Harrison DA, Prabhu G, Grieve R, et al. Risk Adjustment In Neurocritical care (RAIN)--prospective validation of risk prediction models for adult patients with acute traumatic brain injury to use to evaluate the optimum location and comparative costs of neurocritical care: a cohort study. Health Technol Assess. 2013;17:vii-viii, 1-350. doi:10.3310/hta17230

50. Sumann G, Kampfl A, Wenzel V, Schobersberger W. Early intensive care unit intervention for trauma care: what alters the outcome? Curr Opin Crit Care. 2002;8:587-592. doi:10.1097/00075198-200212000-00017

51. Marehbian J, Muehlschlegel S, Edlow BL, et al. Medical management of the severe traumatic brain injury patient. Neurocrit Care. 2017;27:430-446. doi:10.1007/s12028-017-0408-5

52. Munch E, Horn P, Schurer L, et al. Management of severe traumatic brain injury by decompressive craniectomy. Neurosurgery. 2000;47:315-322; discussion 322-313. doi:10.1097/00006123-200008000-00009

53. Bulger EM, Nathens AB, Rivara FP, et al. Management of severe head injury: institutional variations in care and effect on outcome. Crit Care Med. 2002;30:1870-1876. doi:10.1097/00003246-200208000-00033

54. Guidelines for the management of severe head injury. Brain Trauma Foundation, American Association of Neurological Surgeons, Joint Section on Neurotrauma and Critical Care. J Neurotrauma. 1996;13:641-734. doi:10.1089/neu.1996.13.641

55. Brain Trauma Foundation; American Association of Neurological Surgeons; Congress of Neurological Surgeons. Guidelines for the management of severe traumatic brain injury. J Neurotrauma. 2007;24(Suppl 1):S1-S106. doi:10.1089/neu.2007.9999

56. Katz DI, Polyak M, Coughlan D, et al. Natural history of recovery from brain injury after prolonged disorders of consciousness: outcome of patients admitted to inpatient rehabilitation with 1-4 year follow-up. Prog Brain Res. 2009;177:73-88. doi:10.1016/S0079-6123(09)17707-5

57. Giacino JT, Katz DI, Schiff ND, et al. Practice guideline update recommendations summary: disorders of consciousness: Report of the Guideline Development, Dissemination, and Implementation Subcommittee of the American Academy of Neurology; the American Congress of Rehabilitation Medicine; and the National Institute on Disability, Independent Living, and Rehabilitation Research. Neurology. 2018;91:450-460. doi:10.1212/WNL.0000000000005926

58. Granger CV,MarkelloSJ, Graham JE, et al. The uniform data system for medical rehabilitation: report of patients with traumatic brain injury discharged from rehabilitation programs in 2000-2007. Am J Phys Med Rehabil. 2010;89:265-278. doi:10.1097/PHM.0b013e3181d3eb20

59. Turner-Stokes L, Dzingina M, Shavelle R, et al. Estimated life-time savings in the cost of ongoing care following specialist rehabilitation for severe traumatic brain injury in the United Kingdom. J Head Trauma Rehabil. 2019;34:205-214. doi:10.1097/HTR.0000000000000473

60. Cicerone KD, Mott T, Azulay J, et al. A randomized controlled trial of holistic neuropsychologic rehabilitation after traumatic brain injury. Arch Phys Med Rehabil. 2008;89:2239-2249. doi:10.1016/j.apmr.2008.06.017

61. Goodall P, Ghiloni CT. The changing face of publicly funded employment services. J Head Trauma Rehabil. 2001;16:94-106. doi:10.1097/00001199-200102000-00010

62. Ylvisaker M, Todis B, Glang A, et al. Educating students with TBI: themes and recommendations. J Head Trauma Rehabil. 2001;16:76-93. doi:10.1097/00001199-200102000-00009

63. Spearman RC, Stamm BH, Rosen BH, et al. The use of Medicaid waivers and their impact on services. J Head Trauma Rehabil. 2001;16:4760. doi:10.1097/00001199-200102000-00007

64. Cusick CP, Gerhart KA, Mellick D, et al. Evaluation of the home and community-based services brain injury Medicaid Waiver Programme in Colorado. Brain Inj. 2003;17:931-945. doi:10.1080/0269905031000110391

65. Povlishock JT, Katz DI. Update of neuropathology and neurological recovery after traumatic brain injury. J Head Trauma Rehabil. 2005;20:76-94. doi:10.1097/00001199-200501000-00008 
66. Corrigan JD, Zheng T, Pinto SM, et al. Effect of preexisting and co-occurring comorbid conditions on recovery in the 5 years after rehabilitation for traumatic brain injury. J Head Trauma Rehabil. 2020;35:E288-E298. doi:10.1097/HTR.0000000000000521

67. Solmaz B, Tunc B, Parker D, et al. Assessing connectivity related injury burden in diffuse traumatic brain injury. Hum Brain Mapp. 2017;38:2913-2922. doi:10.1002/hbm.23561

68. Kraus MF, Susmaras T, Caughlin BP, et al. White matter integrity and cognition in chronic traumatic brain injury: a diffusion tensor imaging study. Brain. 2007;130:2508-2519. doi:10.1093/brain/awm216

69. Kumar R, Husain M, Gupta RK, et al. Serial changes in the white matter diffusion tensor imaging metrics in moderate traumatic brain injury and correlation with neuro-cognitive function. J Neurotrauma. 2009;26:481-495. doi:10.1089/neu.2008.0461

70. Katz DI, Alexander MP. Traumatic brain injury: predicting course of recovery and outcome for patients admitted to rehabilitation. Arch Neurol. 1994;51:661-670. doi:10.1001/archneur.1994.00540190041013

71. Haslam C, Batchelor J, Fearnside MR, et al. Post-coma disturbance and post-traumatic amnesia as nonlinear predictors of cognitive outcome following severe closed head injury: findings from the Westmead Head Injury Project. Brain Inj. 1994;8:519-528. doi:10.3109/02699059409151004

72. Tate RL, Perdices M, Pfaff A, Jurjevic L. Predicting duration of posttraumatic amnesia (PTA) from early PTA measurements. J Head Trauma Rehabil. 2001;16:525-542. doi:10.1097/00001199-200112000-00002

73. Zafonte RD, Mann NR, Millis SR, et al. Posttraumatic amnesia: its relation to functional outcome. Arch Phys Med Rehabil. 1997;78:11031106. doi:10.1016/S0003-9993(97)90135-0

74. Whyte J, Cifu D, Dikmen S, Temkin N. Prediction of functional outcomes after traumatic brain injury: a comparison of 2 measures of duration of unconsciousness. Arch Phys Med Rehabil. 2001;82:1355-1359. doi:10.1053/apmr.2001.26091

75. Sherer M, Yablon SA, Nakase-Richardson R, Nick TG. Effect of severity of post-traumatic confusion and its constituent symptoms on outcome after traumatic brain injury. Arch Phys Med Rehabil. 2008;89:42-47. doi:10.1016/j.apmr.2007.08.128

76. Sherer M, Yablon SA, Nakase-Richardson R. Patterns of recovery of posttraumatic confusional state in neurorehabilitation admissions after traumatic brain injury. Arch Phys Med Rehabil. 2009;90:1749-1754. doi:10.1016/j.apmr.2009.05.011

77. Nakase-Richardson R, Yablon SA, Sherer M. Prospective comparison of acute confusion severity with duration of post-traumatic amnesia in predicting employment outcome after traumatic brain injury. J Neurol Neurosurg Psychiatry. 2007;78:872-876. doi:10.1136/ jnnp.2006.104190

78. Hammond FM, Hart T, Bushnik T, et al. Change and predictors of change in communication, cognition, and social function between 1 and 5 years after traumatic brain injury. J Head Trauma Rehabil. 2004;19:314-328. doi:10.1097/00001199-200407000-00006

79. Millis SR, Rosenthal M, Novack TA, et al. Long-term neuropsychological outcome after traumatic brain injury. J Head Trauma Rehabil. 2001;16:343-355. doi:10.1097/00001199-200108000-00005

80. Olver JH, Ponsford JL, Curran CA. Outcome following traumatic brain injury: a comparison between 2 and 5 years after injury. Brain Inj. 1996;10:841-848. doi:10.1080/026990596123945

81. Corrigan JD, Smith-Knapp K, Granger CV. Outcomes in the first 5 years after traumatic brain injury. Arch Phys Med Rehabil. 1998;79:298305. doi:10.1016/S0003-9993(98)90010-7

82. Hammond FM, Giacino JT, Nakase Richardson R, et al. Disorders of consciousness due to traumatic brain injury: functional status ten years post-injury. J Neurotrauma. 2019;36:1136-1146. doi:10.1089/neu.2018.5954

83. Multi-Society Task Force on PVS. Medical aspects of the persistent vegetative state (1). N Engl J Med. 1994;330:1499-1508. doi:10.1056/ NEJM199405263302107

84. Estraneo A, Moretta P, Loreto V, et al. Late recovery after traumatic, anoxic, or hemorrhagic long-lasting vegetative state. Neurology. 2010;75:239-245. doi:10.1212/WNL.0b013e3181e8e8cc

85. Giacino JT, Ashwal S, Childs N, et al. The minimally conscious state: definition and diagnostic criteria. Neurology. 2002;58:349-353. doi:10.1212/WNL.58.3.349

86. Luaute J, Maucort-Boulch D, Tell L, et al. Long-term outcomes of chronic minimally conscious and vegetative states. Neurology. 2010;75:246-252. doi:10.1212/WNL.0b013e3181e8e8df

87. Hagen C, Malkmus D, Durham P. Levels of Cognitive Functioning. Ranchos Los Amigos Hospital; 1972.

88. Alexander MP. Traumatic brain injury. In: Benson DF, Blumer D, eds. Psychiatric Aspects of Neurologic Disease. McGraw-Hill; 1982:251-278.

89. Katz DI. Neuropathology and neurobehavioral recovery from closed head injury. J Head Trauma Rehabil. 1992;7:1-15. doi:10.1097/00001199-199206000-00004

90. Giacino JT, Katz DI, Schiff ND, et al. Comprehensive systematic review update summary: disorders of consciousness: Report of the Guideline Development, Dissemination, and Implementation Subcommittee of the American Academy of Neurology; the American Congress of Rehabilitation Medicine; and the National Institute on Disability, Independent Living, and Rehabilitation Research. Neurology. 2018;91:461-470. doi:10.1212/WNL.0000000000005928

91. Sherer M, Katz DI, Bodien YG, et al. Post-traumatic confusional state: a case definition and diagnostic criteria. Arch Phys Med Rehabil. 2020;101(11):2041-2050. doi:10.1016/j.apmr.2020.06.021

92. Stuss DT, Buckle BA. Traumatic brain injury: neuropsychological deficits and evaluation at different stages of recovery and in different pathological subtypes. J Head Trauma Rehabil. 1992;7:40-49. doi:10.1097/00001199-199206000-00007

93. Giacino JT, Kalmar K, Whyte J. The JFK Coma Recovery Scale-Revised: measurement characteristics and diagnostic utility. Arch Phys Med Rehabil. 2004;85:2020-2029. doi:10.1016/j.apmr.2004.02.033

94. Levin HS. The Galveston orientation and amnesia test: a practical scale to assess cognition after head injury. J Nerv Ment Dis. 1979; 167:675684. doi:10.1097/00005053-197911000-00004

95. Laureys S, Celesia GG, Cohadon F, et al. Unresponsive wakefulness syndrome: a new name for the vegetative state or apallic syndrome. BMC Med. 2010;8:68. doi:10.1186/1741-7015-8-68

96. Lehtonen S, Stringer AY, Millis S, et al. Neuropsychological outcome and community re-integration following traumatic brain injury: the impact of frontal and non-frontal lesions. Brain Inj. 2005;19:239-256. doi:10.1080/0269905040004310

97. Martin RM, Wright MJ, Lutkenhoff ES, et al. Traumatic hemorrhagic brain injury: impact of location and resorption on cognitive outcome. J Neurosurg. 2017;126:796-804. doi:10.3171/2016.3.JNS151781

98. Ross BL, Temkin NR, Newell D, Dikmen SS. Neuropsychological outcome in relation to head injury severity. Contributions of coma length and focal abnormalities. Am J Phys Med Rehabil. 1994;73:341-347. doi:10.1097/00002060-199409000-00007 
99. van derNaalt J, Hew JM, vanZomeren $\mathrm{AH}$, etal. Computed tomography and magnetic resonanceimaging in mild to moderatehead injury: early and late imaging related to outcome. Ann Neurol. 1999;46:70-78. doi:10.1002/1531-8249(199907)46:1<70::AID-ANA11>3.0.CO;2-L

100. Levin HS, Williams DH, Eisenberg HM, et al. Serial MRI and neurobehavioural findings after mild to moderate closed head injury. J Neurol Neurosurg Psychiatry. 1992;55:255-262. doi:10.1136/jnnp.55.4.255

101. Wilson JT, Hadley DM, Wiedmann KD, Teasdale GM. Neuropsychological consequences of two patterns of brain damage shown by MRI in survivors of severe head injury. J Neurol Neurosurg Psychiatry. 1995;59:328-331. doi:10.1136/jnnp.59.3.328

102. Wallesch CW, Curio N, Galazky I, et al. The neuropsychology of blunt head injury in the early postacute stage: effects of focal lesions and diffuse axonal injury. J Neurotrauma. 2001;18:11-20. doi:10.1089/089771501750055730

103. Bigler ED. Quantitative magnetic resonance imaging in traumatic brain injury. J Head Trauma Rehabil. 2001;16:117-134. doi:10.1097/00001199-200104000-00003

104. Wallesch CW, Curio N, Kutz S, et al. Outcome after mild-to-moderate blunt head injury: effects of focal lesions and diffuse axonal injury. Brain Inj. 2001;15:401-412. doi:10.1080/02699050010005959

105. Levin HS, Zhang L, Dennis M, et al. Psychosocial outcome of TBI in children with unilateral frontal lesions. J Int Neuropsychol Soc. 2004;10:305-316. doi:10.1017/S1355617704102129

106. Wilde EA, Newsome MR, Bigler ED, et al. Brain imaging correlates of verbal working memory in children following traumatic brain injury. Int J Psychophysiol. 2011;82:86-96. doi:10.1016/j.ijpsycho.2011.04.006

107. Steyerberg EW, Mushkudiani N, Perel P, et al. Predicting outcome after traumatic brain injury: development and international validation of prognostic scores based on admission characteristics. PLoS Med. 2008;5:e165; discussion e165. doi:10.1371/journal. pmed.0050165

108. Collaborators MCT, Perel P, Arango M, et al. Predicting outcome after traumatic brain injury: practical prognostic models based on large cohort of international patients. BMJ. 2008;336:425-429. doi:10.1136/bmj.39461.643438.25

109. Yue JK, Vassar MJ, Lingsma HF, et al. Transforming research and clinical knowledge in traumatic brain injury pilot: multicenter implementation of the common data elements for traumatic brain injury. J Neurotrauma. 2013;30:1831-1844. doi:10.1089/neu.2013.2970

110. Maas AI, Menon DK, Steyerberg EW, et al. Collaborative European NeuroTrauma Effectiveness Research in Traumatic Brain Injury (CENTER-TBI): a prospective longitudinal observational study. Neurosurgery. 2015;76:67-80. doi:10.1227/NEU.0000000000000575 